\title{
Alcohol Consumption and Risk Perception in the Portuguese Construction Industry
}

\author{
Pedro M. Arezes* and Margarida Bizarro
}

Human Engineering Group, School of Engineering, University of Minho, Portugal

\begin{abstract}
Previous studies have demonstrated that some workers tend to ignore the risk that may arise from performing an activity under the influence of alcohol. The main objective of this study was toassess the relationship between the risk perception of a sample of Portuguese construction workers and their reported and measured alcohol consumption. Risk perception and self-reported consumption were evaluated through a questionnaire applied to a sample of 100 construction workers. Simultaneously, the blood- alcohol level of all the study subjects was detected. Given the obtained results, it was possible to conclude that workers with a lower risk perception seem to also be the highest alcohol consumers. The obtained results will, expectantly, help companies create reliable programs to eradicate alcohol consumption at work.
\end{abstract}

Keywords: Alcohol, risk perception, construction.

\section{INTRODUCTION}

In some countries, people tend to consume a regular amount of alcohol daily, whereas in other countries people only drink occasionally. Portugal is at the top of the list of European countries with reference to the self-reported number of days in which alcohol was consumed, with a mean of 22 days per month [1].

Although data regarding workplace alcohol effects or use is not available in Portugal, studies in other countries show that, for example, in the United States, an estimated $15 \%$ of the workforce is directly affected by alcohol use and impairment when at work [2].

The excessive consumption of alcoholic beverages that affect work environments can potentially decrease productivity and result in a general inefficiency. Several studies have indicated that there is a clear association between excessive alcohol consumption and absenteeism rates [3], as well as with other safety related issues, such as higher accident rates, $[4,5]$. This implies a substantial cost for workers, companies and for the social security system $[6,7]$.

In a study by Smith et al. [8], the author's attempted to estimate the percentage of fatal accidents in the USA in which alcohol was reportedly implicated. From this study, it was possible to verify that $38.5 \%$ of the non-intentional injuries that led to death involved people with a Blood Alcohol Concentration $(\mathrm{BAC})>0 \mathrm{mg} / \mathrm{dl}$, and that $31 \%$ of those involved were highly intoxicated $(\geq 100 \mathrm{mg} / \mathrm{dl})$. Cherpitel [9] also analyzed a sample of injured people and verified that they were more likely to report moderate and heavy drinking compared with those without injuries. The same author also concludes that they were also less likely to score high on risk perception. Other studies suggested that almost $40 \%$ of all

*Address correspondence to this author at the Human Engineering Group, School of Engineering, University of Minho, 4800-058Guimarães; Portugal; Tel: +351 253510 340; Fax: +351 253510 343;

E-mail: parezes@dps.uminho.pt industrial injuries and fatalities could be traced to alcohol abuse [10].

Experimental studies, such as the one of Ekhardt et al. [11], have demonstrated that even low BACs could result in cognitive and psychomotor failures, which in turn could increase the risk of injuries. Moreover, alcohol tends to impair job performance not only when it is absorbed into the bloodstream, but also when one has become sober. It is also possible that, in severe and prolonged situations of alcohol consumption, alcohol users may present neurological impairments that mightput them at risk of suffering occupational injuries [10]. Furthermore, it is also possible that the remaining effects of alcohol consumption, such as hangovers, may also put workers at a higher risk [10]. Therefore, alcohol used prior to arriving at the jobsite, or used at the worksite can affect workers during and after the drug's direct effects.

Concerning human performance, alcohol influences cognitive function and psychomotor skills [12]. Similarly, Alcohol might lead to some important cognitive function impairments at several levels, such as information processing, memory, verbal expression, response time, caution, reasoning and recognition skills. The cognitive functions that are most affected are information processing and memory, in particular, working memory. But its effects can also include increasing the time required for input, reflection, information structure and response. Even a low alcohol concentration level may reduce the performance of mental processes such as tracking [13].

The construction industry is one of the most affected sectors by alcohol consumption [14]. Several studies have shown the danger of construction jobs and the high death rates observed in these settings [15]. Apart from environmental factors, age or alcohol consumption also have emerged as key factors.

Construction has always evidenced a culture of tobacco, drug and alcohol use, which is typical for any occupation that employs mainly single young men who often work far from home in high-stress environments and in low-skill jobs 
[16]. It is not surprising that a long list of reports and surveys from Canada and the United States indicate that the construction industry regularly appears at or near the top of job lists with the highest rates of alcohol and drug use [14, 16].

Recent data on alcohol consumption demonstrated that construction workers were reported to be the highest consumers, with more than $65 \%$ of workers reportingthat they regularly consume, and $25 \%$ of them reporting to consume 1 to 4 drinks per day [17]. Construction and mining sectors, together with the transportation sector, are consistently those sectors that present the highest percentage of "problem" drinkers [14]. According to a recent report of the National Survey on Drug Use and Health (NSDUH) [18], the construction sector is at the top of the list of industries with high alcohol consumption, with $15.9 \%$ of consumers, and with nearly one in seven workers presenting a serious alcohol problem, as per data mentioned by Giller [19]. Some studies [20] reported for example, excess alcohol consumption among construction workers and its influence on accidents, and highlighted the role of alcohol among the significant type of work accidents at construction sites, such as serious falls.

A Portuguese study of occupational accidents [21] also referred to the possible role of alcohol on accidents in the construction sector and, more recently, a Spanish study [22] referred the need to measure alcohol consumption among construction workers as a mean towards reducing accident rates.

Despite the mentioned potential effects of alcohol consumption at work, workers do not equally perceive the associated risk and this individual risk perception can be assumed to bea critical antecedent of a worker's risk behaviour [23]. Accordingly, understanding how workers perceive the risks to which they are exposed, can be crucial for a better understanding of risk management, and ultimately, for their own safety [24].

Quantifying risk perception can be accepted as an attempt to explain the extent to which risk perception influences the worker's behaviour and attitudes, namely those regarding the specific risk factors in analysis. It seems reasonable to assume that risk perception in workplaces can, at least to a certain extent, influence workers' behaviour [25].

The main aim of this study then was to characterize alcohol consumption among a sample of construction workers through the use of an alcohol test and in comparison with their self-reported consumption, as well as to analyze the existent relationship between individual risk perception and alcohol consumption.

\section{METHODOLOGY}

\subsection{Sample Description}

This study consisted of a cross-sectional study, which included a sample of construction workers with different types of construction jobs or tasks. In order to accomplish the aim of this study, 107 workers from a single construction company were identified and selected to take part in this study. Later, it was verified that six workers would cease their contract during the period of the study and were therefore excluded from taking part; one worker who participated in the study suffered an accident during the period of the study and consequently was also excluded from the final sample.

All 100 subjects involved were selected based on the risk associated with their specific construction tasks and also with the need to cover a broad range of existing construction jobs. Therefore, and based on a previous risk assessment, only workers involved in construction site tasks were selected. These workers were working at several temporary construction sites and the selection embraced several jobs such as carpenters, electricians, ironworkers, labourers, masonry workers, sheet metal workers and helpers.

The considered sample presented a mean age of 39.3 $( \pm 12.2)$ years and a mean background level of $6.0( \pm 2.0)$ years of schooling, which is low, but typical, in the Portuguese construction industry. Only $5 \%$ of the workers studied beyond the $9^{\text {th }}$ grade, which is currently the minimum background level established in Portuguese legislation.

\subsection{Questionnaire Development and Application}

Aiming to characterize workers and their risk perception, a questionnaire was applied. The development of the questionnaire was initially performed considering two different aspects: the importance and relevance of the studied items and the effort needed to interpret the questionnaire [25]. Understanding the participant sample was crucial, primarily if we take into consideration that more than $85 \%$ of the workers had a background educational level inferior to the basic educational level ( $4^{\text {th }}$ grade).

The questionnaire was directed to all personnel directly involved in the project. The company provided the researchers with a list of all of the employees working on the site. Individuals were supplied with a code number in order to make the matching of observations possible between the measurement occasions. The researchers maintained the connection between code numbers and individual identities strictly confidential. Members of the research team were present during the data collection, which was performed at the construction site.

In a first meeting held to present the project, researchers informed participants that they would ensure that any disclosure of the obtained data or subsequent analysis would not directly be tied to participants. Additionally, the questionnaire header included the following sentence: "Your responses are strictly confidential (so please do not put your name anywhere on this survey or answer sheet)".

In order to improve the quality and reliability of the questionnaire, some preliminary tests were applied in order to detect any interpretation difficulty or misunderstanding. These preliminary tests were carried out with five randomly selected workers from the entire study sample, which resulted in a pilot sample with demographic data similar to the entire sample, with a mean age of 33.1 and an average background level of 6.6 years of education.

As a result of the preliminary test, some items were rephrased or changed several times until the final format was achieved. Additionally, the internal reliability analysis of the used scales was accomplished by the computation of Cronbach's alpha. This analysis computed the total scale alpha values and the alpha value, "if the item is deleted" (alpha item remainder). For the selection of items, a cut-off crite- 
rion was applied. Thus, all the scales should have an internal reliability value of, at least, 0.7 , which is considered to be acceptable, as suggested in several references, such as Spector [27].

The first group of questionnaire questions related to workers' personal data, such as their identification, civil status, professional category and educational level. Data assortment on workers' individual characteristics was gathered to characterize the sample but also to investigate the eventual effect of the workers' age, both on alcohol consumption and risk perception. Literature review on risk perception has revealed that age is, among other individual factors, one of the most cited and is frequently associated with excessive optimism observed mainly in young populations. This could explain the modification of the vulnerability sensation towards specific events or behaviour [28].

In the second group of questions, the questions about workers' involvement in work accidents, self-reported alcohol consumption (both at meals and during work) and risk perception were also included. Self-report data was used considering its presumed validity and reliability regarding alcohol consumption [29].

Risk perception is basically a subjective phenomenon and, according to Sjoberg [30], must be studied with suitable psychological methods, being the most common approach that of a questionnaire [30].

In the present study, the specific content of central interest was that of the perceived risk regarding alcohol consumption at work. To this respect, most work has more broadly sampled expectations of alcohol effects, often using specific developed scales. Accordingly, the risk perception construct used here was developed based on some previous validated scales regarding individual perception of the drinking phenomena, in particular regarding workers' drinking expectations, such as the case of the Drinking Expectancy Questionnaire [30, 31] and the Worry-Reduction Alcohol Expectancy Scale [32].

Additionally, some items were adapted, or rephrased, in order to include some aspects of the typical risky atti- tudes/beliefs reported by alcohol consumers and that were collected during previous interviews performed at the beginning of the study [33]. The complete set of questions related with risk perception is included in Appendix I.

Workers had to classify 15 described statements through a Like rt-type 5 point scale [26], ranging from "Strongly Agree" to "Strongly disagree"; the maximum score was assigned to the most adequate "preventive" attitude/belief and the minimum score assigned to the most "unsafe" attitude. The score varied from -2 to 2 , and 0 was assigned to the "Neither agree nor disagree" option.

\subsection{Alcohol Consumption}

One of the defined methodological approaches consisted of quantifying, as accurately as possible, the alcohol level, or its concentration, in the worker's blood. This was possible through the application of a breath alcohol test.

The applied test consists of a rough estimate of the worker's Blood Alcohol Concentration (BAC) by measuring the amount of alcohol in the air exhaled by the tested person. The equipment used to measure BAC levels was a breath alcohol-testing device, AlcoQuant 3020 (Version 3.13), which was previously verified and calibrated.

All the tests were applied during the work period, using the same equipment, and, whenever possible, at the same time, at approximately 3:00 PM. These requirements are justified in order to establish a similar criterion for all workers and to obtain representative data for the entire sample.

\section{RESULTS}

\subsection{Descriptive Statistics for the Collected Data}

Results from the application of the questionnaire regarding risk perception demonstrated that workers reported a mean risk perception score of $14.2( \pm 6.6)$ points, on a scale ranging from -30 to 30 points. The analysis of the obtained scores has also shown that more than $50 \%$ of workers' scores on this questionnaire were between 10 and 20 points. Accordingly, it is possible to observe that risk perception was reasonably high.

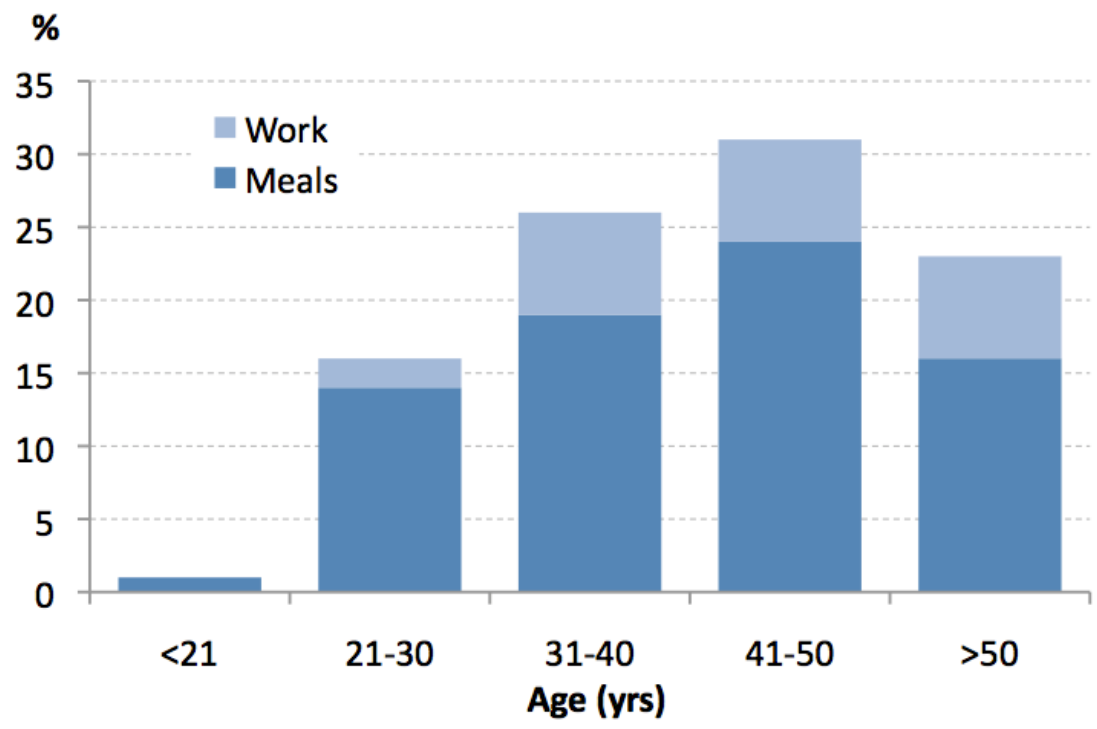

Fig. (1). Self-reported Alcohol consumption (in the \% of the sample) by age category. 


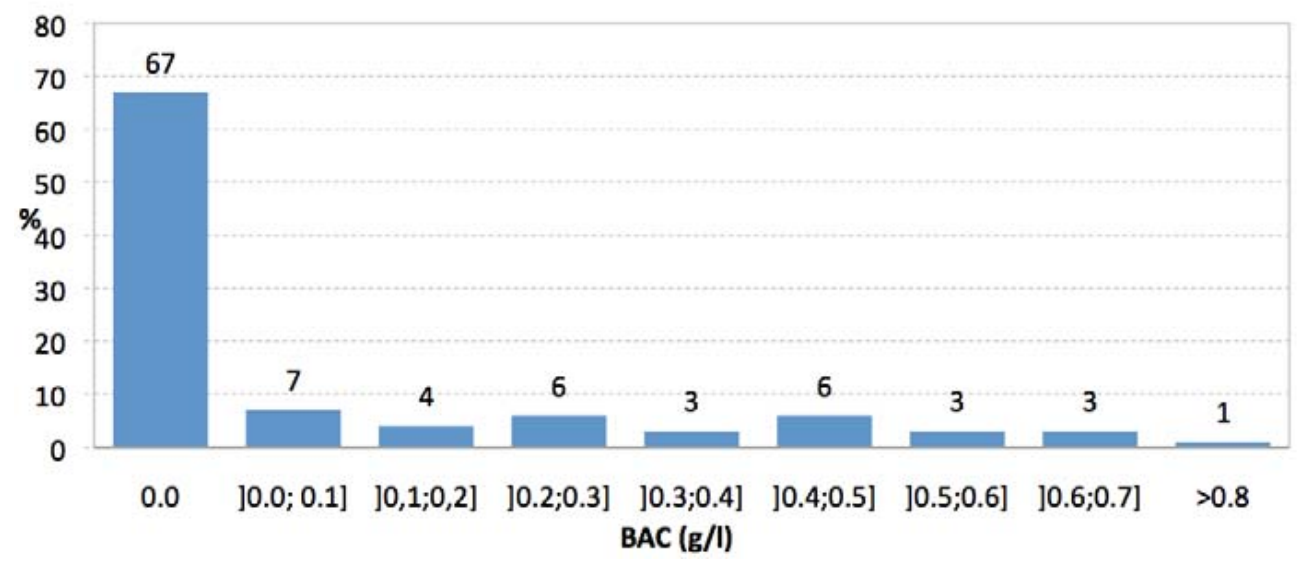

Fig. (2). Histogram of the alcohol test results.

In regards to the self-reported alcohol consumption, the questions were related to drinking practices during work and meals during the workday, and not to the quantity of alcohol consumed (or equivalent). Fig. (1) shows these results by age category.

As illustrated, alcohol self-reported consumption is mainly observed in workers from 41 to 50 years old. Beyond the observed high percentage of alcohol consumers at meals, which in this category is $24 \%$, an additional $7 \%$ of the workers reported to consuming alcohol during work. Globally, $25 \%$ of the workers reported to consume while working and $74 \%$ reported to consume during meals.

As a result of the application of the breath alcohol test, alcohol was detected in one third of the workers, which is expressed by the blood alcohol concentration (BAC), in grams of alcohol per litre of blood.

The overall results are presented in Fig. (2). According to the obtained results, alcohol consumption was detected in 33 workers, and among those, only sevenhad a BAC higher than the $0.5 \mathrm{~g} / \mathrm{l}$, which is the maximum level admissible by law.

\subsection{Statistical Analysis}

Subsequent to the compilation of all of the results, a statistical analysis was performed through the application of SPSS (Version 17.0.0, 2008). The variables considered were:

Riskp Risk perception, expressed by the obtained sum score in the 15 questions used in the questionnaire;

Age Age of the workers, expressed in years;

Blevel Background educational level of the workers;

Alc_w Self-reported alcohol consumption at work;

Alc_m Self-reported alcohol consumption during meals;

Acc Number of accidents in which the worker was involved;

Postv Indication of a positive test, expressed by a BAC higher than $0.5 \mathrm{~g} / \mathrm{l}$.

The correlation between the considered variables assumes a linear relation. As some of the considered variables are binary (yes/no), the Spearman correlation coefficient was used (Table 1). Spearman coefficients express the joint variation of two variables, but it uses the rank values to obtain an estimation of the correlation.

Considering the importance of the risk perception variable, it was decided that a deeper statistical analysis regarding the relationship between this variable and the others should be carried out. In the cases of the binary variables, the applied statistical analysis was the mean difference, according to the previous applied equal variances test. In the case of the background level analysis with more than two categories, a One-way ANOVA was applied. Table 2 shows the score values regarding the risk perception according to the workers' educational level.

In order to analyze the hypothetical differences between the considered groups, a One-way ANOVA was applied, which shows a statistical significant difference $(\mathrm{F}=1.677$; $p=0.043)$ in risk perception when the different background level groups are compared.

As significant differences within the groups $(p<0.05)$ were found, post-hoc comparisons were applied using the Tukey Honestly Significant Difference (HSD) test to detect significant pair wise differences between configurations while adjusting for multiple comparisons. The obtained results on the Tukey post-hoc test revealed that there were only statistical significant $(\mathrm{p}<0.05)$ differences in the mean risk perception score between the " 1 st- 4 th grade" and all the other categories.

For the binary variables, a test for the difference between means was applied. Table $\mathbf{3}$ presents the risk perception data for the different groups considered.

According to the values presented in Table $\mathbf{4}$, a statistical t-test was applied for all the variables in order to determine the statistical meaning for the found differences.

\section{DISCUSSION}

\subsection{Alcohol Consumption and Risk Perception}

According to the score obtained in the risk perception questionnaire (14.2 points on a scale ranging from -30 to 30 points), it is reasonable to conclude that risk perception was reasonably high. 
Table 1. Spearman Correlation Coefficient (rs) Matrix Between Variables $(\mathbf{N}=100)$

\begin{tabular}{|c|c|c|c|c|c|c|}
\hline & Age & Blevel & Alc_w & Alc_m & Acc & Postv \\
\hline \hline Riskp & -0.081 & $0.183^{*}$ & $-0.184^{*}$ & -0.155 & $-0.293^{* *}$ \\
\hline Age & -- & $-0.715^{* *}$ & 0.163 & $0.344^{* *}$ & 0.039 & $0.296^{* *}$ \\
\hline Blevel & & -- & -0.147 & $-0.256^{* *}$ & -0.080 & $-0.351^{* *}$ \\
\hline Alc_w & & & -- & $0.342^{* *}$ & 0.058 & $0.286^{* *}$ \\
\hline Alc_m & & & -- & 0.162 & $0.370^{* *}$ \\
\hline Acc & & & & & -- \\
\hline
\end{tabular}

* Statistically significant at a 0.05 level.

**Statistically significant at a 0.01 level.

Table 2. Risk Perception Score According to Workers' Educational Background Level

\begin{tabular}{|c|c|c|c|}
\hline Category & N & Risk Perception & Mean \\
\cline { 3 - 4 } & & 12.72 & 7.172 \\
\hline \hline 1st-4th grade & 23 & 15.25 & 5.646 \\
\hline 5th-6th grade & 29 & 15.34 & 6.237 \\
\hline 7th-9th-grade & 5 & 16.00 & 7.563 \\
\hline 10th-12th grade & & & \\
\hline
\end{tabular}

Table 3. Risk Perception Results According to the Binary Variables

\begin{tabular}{|c|c|c|c|c|}
\hline \multicolumn{2}{|l|}{ Variable } & \multirow[t]{2}{*}{$\mathbf{N}$} & \multicolumn{2}{|c|}{ Risk perception } \\
\hline & & & Mean & sd \\
\hline \multirow[t]{2}{*}{ Alcohol consumption during work } & Yes & 25 & 12.16 & 6.57 \\
\hline & No & 75 & 14.89 & 6.55 \\
\hline \multirow[t]{2}{*}{ Alcohol consumption during meals } & Yes & 74 & 13.51 & 6.30 \\
\hline & No & 26 & 16.19 & 7.24 \\
\hline \multirow[t]{2}{*}{ Work Accident involvement } & Yes & 12 & 17.08 & 7.00 \\
\hline & No & 87 & 13.95 & 6.43 \\
\hline \multirow[t]{2}{*}{ Positive test } & Yes & 7 & 9.57 & 6.27 \\
\hline & No & 93 & 14.56 & 6.55 \\
\hline
\end{tabular}

Table 4. Results of the t-Test for the Difference Between Means in Risk Perception

\begin{tabular}{|c|c|c|c|}
\hline Variable & Difference & $\mathbf{t}$ & $\mathbf{p}$ \\
\hline Alcohol consumption during work & -2.73 & -1.806 & 0.074 \\
\hline Work accident involvement & 3.13 & 1.564 & 0.121 \\
\hline Positive test & -4.99 & -1.947 & 0.050 \\
\hline
\end{tabular}


$74 \%$ of workers reported that they consumed alcohol during meals, during the workday. Although it is not possible to establish a direct comparison between results, the obtained findings in this study are generally consistent with other studies, namely with the study of Chau et al. [33], in which the authors reported that alcohol consumption in the construction industry, was reported by $86.1 \%$ of the workers (42.3\% reported that they "sometimes" drink while $43.8 \%$ admitted to drinking "Every day"). It is likely that this consumption may play a significant role in the sector's accident rates. Macedo et al. [20] reported an increase in fatal accidents just after lunch and mentioned the possible relationship between this trend and the consumption of alcohol during meals. Lopez et al. [21] reported similar results among Spanish construction workers and concluded that the drinks at meals might also be associated with an increased risk of work accidents.

When testing workers' BAC, only a few workers presented values higher than the maximum admissible by law. Most probably these results are somehow influenced by the fact that most of the tested workers had already been tested on other occasions. This previous experience is due to the procedure adopted by the company to periodically and randomly test workers, consequently making it possible for them to expect this test. However, taking this into account, it is also important to highlight that, even if workers anticipated that they could be tested for alcohol, seven of them presented a BAC level greater than the legally permitted.

A correlation analysis was applied to the variables .A strong correlation ( $r s=-0.293$; $p>0.01$ ) between risk perception and a positive alcohol test result was observed, which is statistically significant and negative; that is, the higher the risk perception, the lower the BAC, and vice-versa. In the same way, and also with a lower significant value (rs=$0.184 ; \mathrm{p}<0.05)$, it is possible to verify that the higher the risk perception is, the lower the alcohol consumption during work (ALC_W) will be. These results seem to support that risk perception and workers' risky behaviour can be related. This relationship has also been observed in other drinking populations [34]. Based on this, it is possible to assume that intervention to reduce drinking on construction sites and among construction workers may be improved by addressing all of the workers' dangerous attitudes and beliefs. However, it should also be recognized that the causal links between alcohol use, workers' risky behaviours and occupational accidents may also include other, untested social, psychological and interactional causal processes [35, 36].

Furthermore, interventions planned for improving risk perception may also result in a reduction of risky behaviour. Those interventions seem to be done more effectively if the safety training of workers also involved these aspects. Considering this, it seems reasonable to assume that training focused on prevention and alcohol consumption control may play a very important role in workers' risk perception. The content of these training programs should include the effects of excessive alcohol consumption (on workers' health, performance, and social life), as well as to clarify some "myths" about alcohol and the establishment of the responsibilities of all the work-site players.

Risk perception is also correlated ( $\mathrm{rs}=0.183$; $\mathrm{p}<0.05)$ to workers' educational background. In this case, the correla- tion is positive, i.e., the higher the background level is, the higher the worker's risk perception will be.

Regarding the variable Age, and beyond some already expected correlations, a positive correlation was observed between age and alcohol consumption during meals and the results of the alcohol test. As the correlation is positive, it means that the self-reported consumption, as well as the real consumption (measured through the applied test), is higher among older workers, and vice-versa.

In what concerns the workers' educational background, the most notorious correlation is the negative correlation between this variable and the alcohol test. This means that the BAC is higher for workers with less education.

The self-reported consumption during meals seems to be correlated with the self-reported consumption during work. Accordingly, those workers who reported a higher consumption of alcohol during meals are the same who presented a higher consumption during work. As expected, there is a positive correlation between alcohol consumption during meals and BAC levels.

In this regard, it is important to emphasize that the majority of construction sites are temporary and do not possess cafeterias, and therefore it is very complex to control workers' alcohol consumption during meals. However, workers should be well informed about the reasonable amount of alcohol they are allowed to drink and should lunch facilities exist, restrict the available alcoholic drinks to this quantity.

Regarding workers' involvement in work accidents, it was verified that no correlation with the other variables was found. Although it could not be confirmed by the available data, the low correlation between accidents and alcohol consumption might be due to the difference between the "real" and the "self-reported" occurrence of accidents. Considering this, it is desirable that future studies on this particular matter should involve written records of workers' accident involvement, and not be exclusively based on self-reported involvement.

In view of this and the fact that Portuguese legislation on accident registry procedures does not require the verification of all of the involved workers' BAC, it should be recommended that all construction companies establish a specific work accident registry procedure that includes when possible, a BAC of the worker(s) involved in an accident.

Finally, and according to the analyses performed, there are no statistical significant differences in risk perception when we consider the variables related with the reported alcohol consumption at work and during meals, as well as the variable related with the occurrence of work accidents. On the contrary, there is a statistical significant difference in risk perception when workers are divided between those who tested positive test in the alcohol breath test and those who $\operatorname{did} \operatorname{not}(\mathrm{p}=0.05)$.

\subsection{Study Limitations}

Regarding the present study, there are two main limitations relating to the analysed data that may affect the accuracy of the results that need to be acknowledged. The first limitation concerns the use of a small sample, which may imply that the obtained results are not representative of the 
entire Portuguese population of construction workers. However, and despite the small sample size, it should be highlighted that the use of such a number of workers is quite common when research includes a demanding data collection procedure. The generalize ability of Portuguese workers to other nationalities is also unknown.

The second limitation is related to the first and has to do with the homogeneity characteristics of the used sample. The obtained data might not represent the entire studied population. Despite the limited value of the results, these data are very important in understanding the analysed topic, especially considering that currently no additional data exists regarding the alcohol consumption at construction sites and how that relates with other variables, such as individual risk perception. This study can be considered as a starting point, and the obtained data can be used to support a future broader study with a large number of companies.

\section{CONCLUSIONS}

This paper focused on the analysis of the relationship between the risk perception reported by construction workers and their alcohol consumption, assessed by self-reported measures and by a portable BAC test.
From the obtained results, it can be concluded that workers with a lower risk perception seem to also be the highest alcohol consumers. Also, the relationship between risk perception and alcohol consumption is only statistically supported when the alcohol consumption is measured objectively, therefore excluding the self-reported consumption, both during meals and/or during working hours.

Based on the obtained results and discussion, it is likely that interventions to reduce alcohol consumption at construction sites and among construction workers can be improved by considering the impact of their previous experiences and (erroneous) beliefs. This seems to be done more effectively if workers' risk perception is addressed and, in accordance, it is reasonable to assume that training actions focusing on individual risk perception concerning prevention and alcohol use control may influence workers' behavior, as a result indispensable for future safety programs on this issue. While its use in construction varies by nation, alcohol is a relative untested probable cause of occupational safety and health risk. This study represents an important step in understanding the phenomenon and how to intervene.

\section{APPENDIX I}

\section{Risk Perception Questions}

Whether or not you have ever drunk during your work activities, please rate to what extent you Agree/Disagree with each statement by using the proposed scale. Answer the questionnaire based on your own personal thoughts or beliefs.

1= Strongly disagree; $2=$ Disagree; $3=$ Neither agree nor disagree; $4=$ Agree $; 5=$ Strongly agree.

\begin{tabular}{|c|c|c|c|c|c|}
\hline \multirow[b]{2}{*}{ Alcohol helps me have more strength } & \multicolumn{5}{|c|}{ Answer } \\
\hline & 1 & 2 & 3 & 4 & 5 \\
\hline I avoid drinking when working with dangerous equipment & 1 & 2 & 3 & 4 & 5 \\
\hline The best way to satisfy my thirst on hot days is to drink a few cold beers & 1 & 2 & 3 & 4 & 5 \\
\hline Drinking makes me feel calm & 1 & 2 & 3 & 4 & 5 \\
\hline I think that it is too dangerous to work with a colleague under the effect of alcohol & 1 & 2 & 3 & 4 & 5 \\
\hline Drinking makes me feel outgoing and friendly & 1 & 2 & 3 & 4 & 5 \\
\hline I feel powerful when I drink, as if I can really influence others to do what I want & 1 & 2 & 3 & 4 & 5 \\
\hline When I'm drinking, I take extra care of myself and my possessions & 1 & 2 & 3 & 4 & 5 \\
\hline I get better ideas when I am drinking & 1 & 2 & 3 & 4 & 5 \\
\hline My worries about safety are less intense when I drink & 1 & 2 & 3 & 4 & 5 \\
\hline When I drink alcohol, I get more easily confused & 1 & 2 & 3 & 4 & 5 \\
\hline
\end{tabular}




\section{REFERENCES}

[1] ERSO - European Road Safety Observatory. Prevalence \& rate of alcohol consumption - Alcohol consumption [Online]. 2008 Nov 20 [cited 2009]. Available from: http://www.erso.eu/index.html

[2] Frone MR. Prevalence and distribution of alcohol use and impairment in the workplace: A U.S. National Survey. J Stud Alcohol 2006; 76:147-56.

[3] Klingemann H, Sobell L, Barker J, et al. Promoting self-change from problem substance use: Practical implications for policy, prevention and treatment. Kluwer Academic Publishers 2001.

[4] Hanson M. Overview on drug and alcohol testing in the workplace. Bull Narc 1993; 45: 3-44.

[5] Kaestner R, Grossman M. The effect of drug use on workplace accidents. Lab Econ 1998; 5: 267-94.

[6] Jeremy D, Obst P \& Sheehan M. The use of AUDIT as a screening tool for alcohol and mortality - with focus on wine. J Int Med 2000; 250: 291-308.

[7] Moore S, Grunberg J, Greenberg E. The relationships between alcohol problems and well-being, work attitudes, and performance: are they monotonic? J Subst Abuse 2000; 11: 183-204.

[8] Smith G, Branas C, Miller T. Fatal non traffic injuries involving alcohol: A meta analysis. Ann Emerg Med 1999; 33: 659-68.

[9] Cherpitel CJ. Alcohol, injury, and risk-taking behavior: data from a national sample. Alcohol Clin Exp Res1993; 17: 762-6.

[10] Zwerling C. Current practice and experience in drug and alcohol testing in the workplace. Bull Narc 1993; 45: 155-96.

[11] Eckhardt M. Effects of moderate alcohol consumption on the central nervous system. Alcohol Clin Exp Res 1998; 22: 998-1040.

[12] Kim H, Yang C, Lee B, Yang Y, Hong S. Alcohol effects on navigational ability using ship handling Simulator. Int J Ind Ergonomics 2007; 37: 733-43.

[13] Newman D. Alcohol and human performance from an aviation perspective: A Review Research Report, Australian Transport Safety Bureau (ATSB) 2004.

[14] Mandell W, Eaton W, Anthony J, Garrison R. Alcoholism and occupations: a review and analysis of 104 occupations. Alcohol Clin Exp Res 1992; 16: 734-46.

[15] Lipscomb H, Dement J, Rodriguez-Acosta R. Deaths from external causes of injury among construction workers in North Carolina, 1988-1994. Appl Occup Environ Hyg 2000; 15: 569-80.

[16] Bula F. Construction culture heavy into alcohol and drugs. Canada: The Leader-Post, (published in 29/09/2007), 2007.

[17] Petersen JS, Zwerling C. Comparison of health outcomes among older construction and blue-collar employees in the united states. Am J Ind Med 1998; 34: 280-7.

[18] SAMHSA - Substance Abuse and Mental Health Services Administration. National Survey on Drug Use \& Health [Online]. 2007 [cited 2009]. Available from: http://www.oas.samhsa.gov/nsduh. htm
[19] Giller J. Construction and mining, wholesale, retail top list of industries. ensuring solutions to alcohol problems. Washington, D.C.: The George Washington University Medical Centre 2005.

[20] Lipscomb HJ, Dement JM, Rodriguez-Acosta R. Deaths from external causes of injury among construction workers in north carolina, 1988-1994. Appl Occup Environ Hyg 2000; 15: 569-80.

[21] Macedo A, Silva I. Analysis of occupational accidents in Portugal between 1992 and 2001. Saf Sci 2005; 43: 269-86.

[22] Lopez MC, Ritzel DO, Fontaneda I, Gonzalez Alcantara OJ. Construction industry accidents in Spain. J Saf Res 2008; 39: 497-507.

[23] Glendon I, McKenna E. Human Safety and Risk Management. Chapman \& Hall, London 2005.

[24] Rundmo T. Associations between risk perception and safety. Saf Sci 1996; 24: 197-209.

[25] Stewart-Taylor A, Cherrie JW. Does risk perception affect behaviour and exposure. A pilot study amongst asbestos workers. Ann Occup Hyg1998; 42: 565-9.

[26] Arce C. Técnicas de Construcción de Escalas Psicológicas, Metodologias de las ciencias del comportamento. Madrid, Spain: Sintesis Psicologia 1994.

[27] Spector PE. Summated rating scale construction: an introduction. LOCAL: Sage University Papers 1992.

[28] Rundmo T, Ulleberg P. Attitudes, behaviour and risk perception among young norwegian drivers: proceedings of society for risk analysis-Europe Annual Meeting 1999.

[29] Midanik L. Validity of self-reported alcohol use: a literature review and assessment. Addiction 1988; 83: 1019-29.

[30] Sjoberg L. Risk perception of alcohol consumption. Alcohol Clin Exp Res 1998; 22: 277-84.

[31] Young RM, Knight RG. The drinking expectancy questionnaire: a revised measure of alcohol-related beliefs. J Psychopathol Behav1989; 11: 99-112.

[32] Smith JP, Tran GQ. Development and initial validation of the worry-reduction alcohol expectancy scale. Addict Behav 2007; 32: 2383-90.

[33] Bizarro M. Caracterização do consumo de bebidas alcoólicas durante a realização de trabalho na construção civil: implicações para a segurança ocupacional. MSc. Thesis (not published), University of Minho, Portugal 2008 (in Portuguese).

[34] Chau N, Gauchard G, Siegfried C, et al. Relationships of job, age, and life conditions with the causes and severity of occupational injuries in construction workers. Int Arch Occup Environ Health 2004; 77: 60-66.

[35] Testa M, Reifman A. Individual differences in perceived riskiness of drinking in pregnancy: antecedents and consequences. J Stud Alcohol 1996; 57: 360-7.

[36] Pernanen K. Causal attributions in the explanation of alcoholrelated accidents. Addiction 1993; 88: 897-906.

(c) Arezes and Bizarro; Licensee Bentham Open.

This is an open access article licensed under the terms of the Creative Commons Attribution Non-Commercial License (http://creativecommons.org/licenses/by-nc/3.0/) which permits unrestricted, non-commercial use, distribution and reproduction in any medium, provided the work is properly cited. 